\title{
What Kind Of International Interchange Is Beneficial? Experiences Of Taiwanese Indigenes
}

\author{
Shan-Hua Chen, National Chiayi University, Taiwan
}

\begin{abstract}
Because of globalization, international interchanges among indigenes in every country have become more frequent. Influenced by international multicultural trends, Taiwan's government not only supports indigenous populations to revive their traditional cultures, but also encourages the promotion of the international interchange activities among indigenous populations. This research focused on specialists familiar with indigenous relative affairs to evaluate the benefits and the order of international interchanges. A self-developed questionnaire was used and the analytic hierarchy process $(A H P)$ and descriptive statistics were employed to measure the relative importance of the factors and international strategies chosen by the indigene affair specialists, respectively. The correspondence analysis aims to explore the relationship between the goal and strategy of indigenous international interchanges. Finally, based on the findings and discussion, some suggestions are provided for promoting indigenes' international interchanges.
\end{abstract}

Keywords: International Activities; Indigenous Affair Specialists; Analytic Hierarchy Process (AHP)

\section{INTRODUCTION}

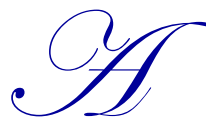

$\mathrm{s}$ a result of globalization, international interchanges among domestic countries have become more frequent. Various international interchanges, such as cultural interchanges and indigenous artistry exhibits, not only bring the culture of the minority public to the majority people, but also boost local tourism. In the past, Taiwan's indigene reservations were passed over for the majority of society in terms of modern development. However, influenced by international multicultural trends, Taiwan's government has followed with interest in the rights and development of indigenous populations in the last 20 years.

In 1996, Taiwan's government set up the Council of Indigenous Peoples, Executive Yuan, which is the highest authority responsible for indigenous affairs. The Indigenous Education Bill was legislated for the indigenous populations in 2005, providing the origin of laws to promote indigenous culture development. According to Article 2 of this law, the indigenous population is the subject of the indigenous education, and the government should be based on multivariate, equality, autonomy, and esteem in order to develop indigenous education. In 2011, the "White Paper of the Indigenous Education" announced the direction of Taiwan's indigenous education development (MOE, 2011).

Although international interchange has become a significant issue, no study has yet examined indigenous international interchange. Therefore, the indigenous problems in every domestic country can refer to and learn from the experiences of every country's indigenous development. The global indigenous population accounts for about $5 \%$ of the global population and the development of domestic indigenes is influenced by international trends. In politics, Taiwan's international interchange achieves the goals of promoting self-confidence and consciousness, enhancing indigenes' international visibility, and uniting global indigenes to face problems. The minority nationality in every country faces similar problems. The United Nations Declaration on the Rights of Indigenous Peoples was adopted by the United Nations General Assembly in September 2007 (United Nations, 2007). The rights affirmed in the declaration included the self-determination and autonomy in politics, economics, and culture. The purpose of 
adopting the UN declaration is to establish the principles for compensating indigenous people who have suffered injustice in the past and to build up the ideal society that achieve ethnic equality, harmony, mutual recognition, and respect (UNESCO, 2007).

The United Nations Permanent Forum on Indigenous Issues (UNPFII) is the consulting organization established by the United Nations. Issues are discussed every year in UNPFII and concluded in the decade declaration (UNESCO, 2013a). In this way, UNPFII gathers experts around the world to discuss the issues about indigenous traditional culture and intellectual property. Most important of all, it provides opportunities for indigenes around the world to interact with voice and pressure multinational corporations in order to achieve their rights (Psacharopoulos \& Patrinos, 1994). Participating in international organizations is helpful in uniting global indigenous people to face the common problems and enhance their own ethnic consciousness.

In parallel with international trends, Taiwan injects resources into and protects indigenous culture through educational efforts. Taiwan's indigenous development emphasizes the cultivation of specialists. From 1997 to 2008, the government provided study abroad scholarships for indigenes to earn postgraduate degrees, increasing the number awarded by 8 to 12 recipients every year (MOE, 2011). Although Taiwan is not a member of the United Nations, to promote international interchanges of the indigenes, the government also prepares a budget to support the colleges to participate in the World Indigenous Higher Education Federation's annual conference. Furthermore, the international visibility of the Taiwanese indigenous population can be improved by learning the successful cases of other countries and sharing the experiences in Taiwan during the exchanges with other countries. It is important to participate in indigenous organizations and mobilize international cooperation.

In economic aspects, international interaction is able to enhance indigenous populations' competitiveness in the labor market, boost indigenes' tribe tourism, and expand indigenes' property international sales. The global indigenous populations face the same situation - after the industrial revolution, colonists forced indigenous peoples to change their lifestyles and cultures to be more in line with the colonists' cultures and fit in with capitalist societies. Although indigenous people were allowed to stay in the original place, they not only lost their land, but also become cheap laborers, losing their land rights while their lifestyles were totally reversed. As indigenous people became economically disadvantaged, each country and UNPFII had to focus on making them more competitive in the labor market (Psacharopoulos \& Patrinos, 1994).

Taiwan held its Austronesia Cultural Arts Festival for the first time in 1999 and, subsequently, regularly invited many indigenous peoples from other countries to engage in cultural interaction (Austronesia Cultural Arts Festival, 2012). The festival serves to reinforce cultural and economic interactions that can boost the tribe's tourism and increase their incomes. In addition, Taiwan and New Zealand signed the ANZTEC (Agreement between New Zealand and the Separate Customs Territory of Taiwan, Penghu, Kinmen, and Matsu on Economic Cooperation) in 2013. The agreement's "Cooperation on Indigenous Issues" includes boosting the trade relationship between Taiwan indigenes and the Māori people, New Zealand's indigenous population, by enhancing mutual benefits (MOEA, 2013). Moreover, raising the intentional market visibility of indigenes' products and merchandise expands the available market range of marketing and trading. Furthermore, encouraging both sides' personnel, information, and industrial knowledge boosts Taiwan's indigenes' industrial abilities. Finally, free trade benefits both sides and creates opportunities for direct trade, lower prices, and real insurance (CNA, 2013). These international interactions are absolutely meaningful to the indigenous populations.

In terms of cultural aspects, international interactions are able to promote learning abroad to help indigenes develop their experiences, share and trace the origins of indigenes' wisdom, and promote the appreciation of and respect for the global indigenous culture. Modern civilization cannot only destroy indigenes' lives, but also cause the traditional culture to vanish. Ethnic languages and cultures are the key points for retaining indigenous cultures. Thus, it is urgent to enhance the indigenous knowledge conveyed, strive to incorporate indigenous language and knowledge into school courses, and mix the learning with the social system (UNESCO, 2013b). As a result, international seminars have sought to save endangered languages, passing down the indigenous wisdom and preserving cultural property. During the seminars, international attendees share their experiences in protecting indigenes' traditions and making other countries respect and value others' cultures in the process of cultural interactions. 
Taiwan's indigenous population belongs to the Austronesian family and shares commonalities with other countries' indigenous populations. For example, the residents on Orchid Island in Taiwan and those on the Philippines Bataan Islands have a $60 \%$ similarity in their languages. According to the orally transmitted literature, the ancient Bataan people migrated to Orchid Island after a tsunami. In TaoTau's oral history, a folk story pointed out that their ancestors were from Bataan (Chen, 2012). Thus, the two places have engaged in traditional culture interactions formally and continuously (Yang, 2012).

Indigenes' international interchanges can be subtyped into three categories - politics, economics, and culture. Thus far, no research has tried to closely examine the benefits of international interchanges for indigenes or to carefully consider whether the limited funding is being spent adequately and effectively. Therefore, it is important to evaluate whether the actual exchanges accomplish the presumed political, economic, and cultural benefits in order to enhance the impact of international interchanges. As a result, this study seeks to achieve three purposes: 1) identify key factors affecting the development of the indigenous international interchanges in Taiwan, 2) calculate the relative importance of each factor, and 3) highlight the opinions of specialists regarding the goals and appropriate implementation methods of international exchanges. Finally, based on the findings and discussion, some suggestions for improving the international interchanges of Taiwanese indigenes are provided.

\section{METHODOLOGY}

\section{Analytic Hierarchy Process}

AHP can be used to calculate the international interchange's goals, which indigenous experts determine at the highest level, whereas secondary goals at the second level are vested in the main objectives. Based on the AHP, one can ascertain the level of each sub-goal score and determine the weight of each level to evaluate goals. The hierarchy makes it possible to establish the relative weight between the goal and the criterion. People's thoughts include complex criteria to make comparisons between two goals and two principles using nine criteria. This approach makes the evaluation from survey items more reasonable while decreasing logical mistakes. Finally, the perception that integrates different policies by ordering the weighted average number indicates that the weight of the decision takes account of each criterion (Saaty, 1980).

The relative weight of the attributes is obtained by comparing them in pairs; a positive reciprocal matrix is then adopted to calculate the relative weights of each factor. The formula used in this research is depicted in Figure 1 , where "aij" represents the element located in row $i$ and column $j$ of the positive reciprocal matrix and "akj" represents the element located in row $k$ of any normalized column $j$.

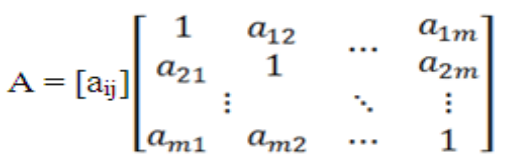

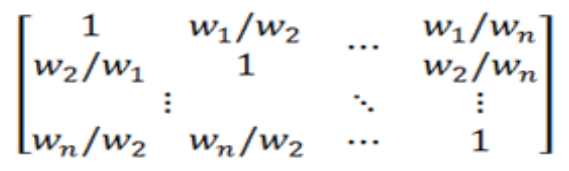

$$
\begin{aligned}
& \text { The weight is: } \mathrm{Wi}=1 / \mathrm{m} \quad \sum_{j=\mathbf{1}}^{m} \frac{a_{i j}}{\sum_{k=\mathbf{1}}^{m} a_{k j}}
\end{aligned}
$$

Figure 1: Formula Used to Calculate the Weights of the Attributes

Next, an eigenvector $\lambda_{\max }$ is calculated to assess the consistency. A CR $<.1$ indicates the consistency of the structure. The formula used in this research is depicted in Figure 2. 


$$
\begin{gathered}
\mathrm{A} \times \mathrm{K}=\left[\begin{array}{cccc}
1 & a_{12} & \ldots & a_{1 m} \\
a_{21} & 1 & & a_{2 m} \\
& \vdots & \ddots & \vdots \\
a_{m 1} & a_{m 2} & \cdots & 1
\end{array}\right] \times\left[\begin{array}{c}
w_{1} \\
w_{2} \\
\vdots \\
w_{m}
\end{array}\right]=\left[\begin{array}{c}
w_{1}^{\prime} \\
w_{2}^{\prime} \\
\vdots \\
w_{m}^{\prime}
\end{array}\right] \\
\lambda_{\max }\left(\frac{1}{\mathrm{~m}}\right) \times\left(\frac{\mathbf{w}^{\prime}}{\mathbf{w}_{1}}+\frac{\mathbf{w}^{\prime}}{\mathbf{w}_{2}}+\frac{\mathbf{w}_{m}^{\prime}}{\mathbf{w}_{m}}\right) \\
\mathrm{CI}=\frac{\lambda \max -m}{m-1} \quad \mathrm{CR}=\frac{\mathrm{CI}}{\mathrm{RI}}
\end{gathered}
$$

Figure 2: Formula Used to Calculate the Consistency of the Model

Next, a final AHP structure was constructed to guide this research. In Figure 3, the main goal, located at the topmost level (in the far left), is to calculate the benefit of an indigenous international interchange. The second level of the hierarchy consists of three major levels - benefit of politics, benefit of economy, and benefit of culture - and the third level consists of nine determinant factors.

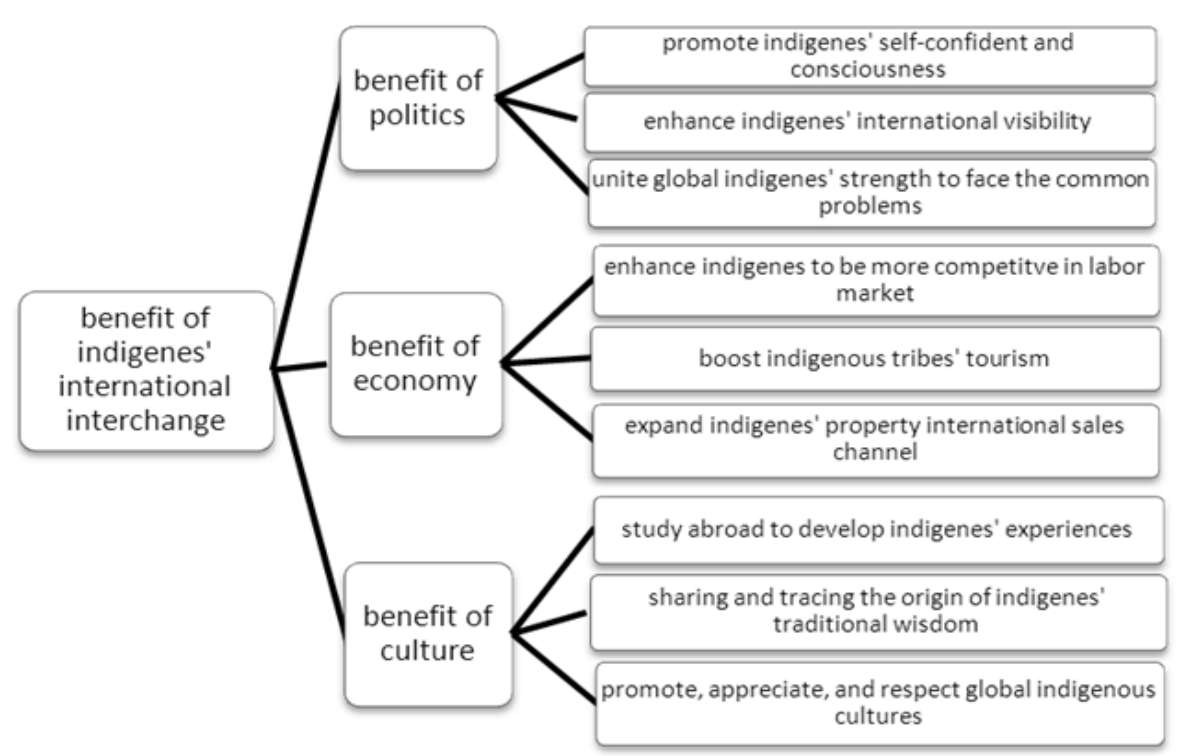

Figure 3: AHP Structure Used in this Research

\section{Design of the Questionnaire}

This study used an author-developed questionnaire which was designed after a literature review, and the construct validity was established after a full discussion of the content by the research team and some indigenous officials. The questionnaire consists of three parts. The first part relates to the fundamental backgrounds of the indigenous affair specialists. The second part was made by first collecting the choices of the specialists on the questionnaires and then calculating the weight placed on the benefits of international interchanges at the political, economic, and cultural levels. Next, nine items (see Figure 3) were used so that the research participants could complete the pairwise comparisons and then, by weight, calculate the scores of the goals of each level, listing these out. The third part - also a self-developed questionnaire - listed out eight common international interchange objectives, including (a) invite minorities from other countries to the international conference, (b) invite every country's indigenous groups to Taiwan to join various cultural activities, (c) encourage indigenes to attend other countries' international conferences, (d) encourage indigenes to join various cultural activities, (e) conduct actions 
with the minority's nationality, culture, international interflow, and investigations, (f) nominate indigenous representative to join every country's economic and trade factions conference, (g) support indigenous international affairs training, and $(\mathrm{h})$ encourage indigenous populations to join international organizations. Indigene affair specialists have conducted self-assessments on the domestic implementation of international interchanges.

In this study, AHP was adopted to measure the relative importance of the factors and international strategies chosen by experts and officials. In addition, CA was used to explore the relationship between the aims and strategies of the indigenous international interchanges.

\section{Research Participants}

Questionnaires were sent to 78 indigenous affair specialists, including academic scholars and government officials involved in the business of the indigenous international interchanges in Taiwan. Forty-five were returned, resulting in a response rate of $58 \%$.

\section{RESEARCH RESULTS}

\section{Participants' Demographic Characteristics}

Forty-five individuals completed the questionnaire, including scholars (76\%), government officials (4\%), and aboriginal cultural workers (20\%). Women accounted for $25 \%$ and men accounted for $75 \%$ of all participants. In addition, $89 \%$ had participated in indigenous international activities in Taiwan, while $62 \%$ had gone abroad to participate in indigenous activities.

\section{Perceptions at Various Levels}

AHP was adopted to calculate the weight of the levels (the second level) and the sub-goals of promoting indigenous international exchanges (the third level). The CR value of $0.007(<0.1)$ corresponds to the consistency test that Satty (1980) suggested. According to the specialists, each level of international interchange carries specific benefits, as outlined in Table 1 .

Table 1: Weights of the Three Levels for the Indigene Specialists

\begin{tabular}{|c|c|c|c|c|}
\hline First Level & CR & Second Level & Weight & Order \\
\hline \multirow{3}{*}{ Benefits } & \multirow{2}{*}{0.007} & Politics & 0.28 & $(3)$ \\
\cline { 2 - 5 } & $(<0.1)$ & Economy & 0.31 & $(2)$ \\
\cline { 2 - 5 } & & Culture & 0.41 & $(1)$ \\
\hline
\end{tabular}

Table 1 indicates that, regarding international interchanges, the specialists give the following weights in order of benefit of the cultural (0.41), economic (0.31), and political (0.28) level. The specialists of indigenous affairs placed more emphasis on international interchanges at the cultural levels.

Table 2: Weights of the Nine Benefits

\begin{tabular}{|c|c|c|c|c|c|}
\hline $\begin{array}{l}\text { First } \\
\text { Level }\end{array}$ & $\begin{array}{c}\text { Second } \\
\text { Level }\end{array}$ & Third Level & $\begin{array}{l}\text { Original } \\
\text { Score }\end{array}$ & Weight & Order \\
\hline \multirow{9}{*}{ Benefits } & \multirow{3}{*}{ Politics } & 1. promote indigenes' self-confidence and consciousness & 0.579 & 0.162 & (3) \\
\hline & & 2. enhance indigenes' international visibility & 0.180 & 0.050 & (9) \\
\hline & & 3. unite global indigenes to face common problems & 0.241 & 0.067 & $(7)$ \\
\hline & \multirow{3}{*}{ Economy } & $\begin{array}{l}\text { 4. enhance indigenes to be more competitive in the labor } \\
\text { market }\end{array}$ & 0.537 & 0.166 & (2) \\
\hline & & 5. boost indigene tribes' tourism & 0.254 & 0.078 & $(6)$ \\
\hline & & 6. expand indigenes' property international sales & 0.209 & 0.064 & $(8)$ \\
\hline & \multirow{3}{*}{ Culture } & 7. study abroad to develop indigenes' experiences & 0.260 & 0.107 & $(5)$ \\
\hline & & 8. share and track origins of indigenes' wisdom & 0.461 & 0.190 & (1) \\
\hline & & $\begin{array}{l}\text { 9. promote, appreciate, and respect global indigenous } \\
\text { cultures }\end{array}$ & 0.279 & 0.115 & (4) \\
\hline
\end{tabular}


Table 2 also provides a comparison of the weights given to the sub-goals. The highest scores were achieved by the following three sub-goals: 8 - share and track origins of indigene's wisdom $(0.190), 4$ - enhance indigenes to be more competitive in the labor market (0.166), and 1 - promote indigenes' self-confidence and consciousness (0.162). Meanwhile, the lowest scores were achieved by the following three sub-goals: 2 - enhance indigenes' international visibility (0.05), 6 - expand indigenes' property international sales (0.064), and 3 - unite global indigenes to face common problems (0.067). Two of the least important factors are from the political level.

\section{Indigenous Affair Specialists' Perceptions of International Interchanges}

As summarized in Table 3, the enhanced performance of methods implemented for the indigenous experts' perceptions of international interchanges is ranked as follows: (b) invite every country's indigenous groups to Taiwan to join various cultural activities (2.98), (e) conduct actions with the minority's nationality, culture, international interflow, and investigations (2.89), (d) encourage indigenes to join various cultural activities (2.87), and (a) invite minorities from other countries to the international conference (2.65). The lowest ranked perceptions are (f) nominate indigenous representative to join every country's economic and trade factions conference (2.28), (h) encourage indigenous populations to join international organizations (2.50), and (c) encourage indigenous to attend other countries' international conferences (2.57).

The greatest divergence in experts' perceptions occurred in three activities - (g) support indigenous international affairs training (1.145), (h) encourage indigenous populations to join international organizations (1.090), and (f) nominate indigenous representative to join every country's economic and trade factions conference (1.026).

Table 3: International Interchanges Perceived by Indigenous Experts

\begin{tabular}{|c|c|c|}
\hline $\begin{array}{l}\text { International Interchanges } \\
\end{array}$ & Average & SD \\
\hline (a) invite minorities from other countries to the international conference & 2.65 & .822 \\
\hline (b) invite every country's indigenous groups to Taiwan to join various cultural activities & 2.98 & .802 \\
\hline (c) encourage indigenes to attend other countries' international conferences & 2.57 & .958 \\
\hline (d) encourage indigenes to join various cultural activities & 2.87 & .806 \\
\hline (e) conduct actions with the minority's nationality, culture, international interflow, and investigations & 2.89 & .924 \\
\hline (f) nominate indigenous representative to join every country's economic and trade factions conference & 2.28 & 1.026 \\
\hline (g) support indigenous international affairs training & 2.61 & 1.145 \\
\hline (h) encourage indigenous populations to join international organizations & 2.50 & 1.090 \\
\hline
\end{tabular}

\section{Results of the Correspondence Analysis}

The $\mathrm{X}^{2}$ of 258.710 and the $\mathrm{CR}$ value of .000 revealed that the perceptual map created using CA was feasible. The results of correspondence between the objectives and methods of indigenous international interchanges implemented are shown in Figure 4. The four types of correspondences are as follows:

1. $\quad \mathrm{b}, \mathrm{d}$, e and 8, 9: The methods of (b) invite every country's indigenous groups to Taiwan to join various cultural activities, (d) encourage indigenes to join various cultural activities, and (e) conduct actions with the minority's nationality, culture, international interflow, and investigations, will help achieve the objectives of (8) sharing and tracking origins of indigenes' wisdom and (9) promoting, appreciating, and respecting global indigenous cultures.

2. 1, 2, 7 and c, a: The objectives of (1) promote indigenes' self-confidence and consciousness, (2) enhance indigenes' international visibility, and (7) study abroad to develop indigenes' experiences correspond to the methods of (c) encouraging indigenes to attend other countries' international conferences and (a) inviting minorities from other countries to the international conference.

3. 3 and h: The objective (3) unite global indigenes to face the common problems is highly related with the method of (h) encourage indigenous populations to join international organizations.

4. 6,4 , and f: The objectives of (6) expand indigenes' property international sales and (4) enhance indigenes to be more competitive in the labor market correspond with the methods of (f) nominating indigenous representatives to join every country's economic and trade factions conference. 
Such correspondences are likely to provide some suggestions for domestic indigenous policy implemented and the related activities based on the objectives. Figure 4 further indicates that the effectiveness of the method $(\mathrm{g})$ support indigenous international affairs training is not helpful for achieving any objective of international interchanges. In addition, despite all eight methods, objective (5) boost indigene tribes' tourism cannot be achieved.

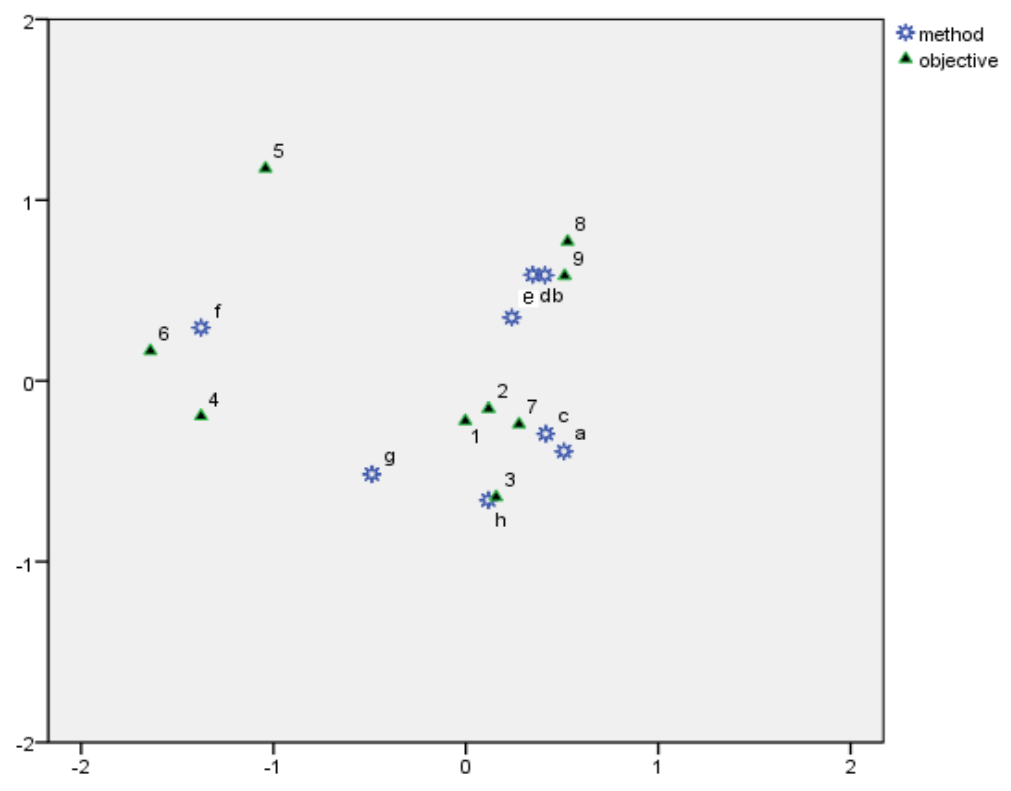

Figure 4: Correspondence between Indigenous International Objectives and Methods

Note: (a) join international conferences, (b) join the cultural activities, (c) encourage indigenes to attend international conferences, (d) encourage indigenes to join cultural activities, (e) culture international interflow and investigate, (f) join economic and trade factions conference, (g) support international affairs training, (h) join international organizations; (1) promote self-confidence and consciousness, (2) enhance international visibility, (3) face common problems, (4) be more competitive in labor market, (5) boost tribes' tourism, (6) expand international property sales, (7) learn developing experiences, (8) share wisdom, (9) appreciate and respect cultures

\section{CONCLUSION AND DISCUSSIONS}

The government announced that 14 races of indigenes exist in Taiwan, accounting for $2 \%$ of the nation's population. Their interactions in international activities will be helpful for thinking about Taiwan's indigenes' problems and promote continuous activities.

Based on the weights, the greatest values for indigenes in promoting international interchanges are tracking wisdom, enhancing indigenes to be more competitive in the labor market, and promoting self-confidence and consciousness. In terms of culture, Taiwan's government invested more funds and resources to actively protect the indigenous cultures and hold several formal interaction activities. In terms of economics, it is likely to enhance indigenes to be more competitive in the labor market through international interactions to expand their international vision. In terms of politics, promoting indigenes' self-confidence and consciousness is an important task. Through the three aspects, the effectiveness of international interactions is greatest.

The effectiveness of enhancing international visibility, expanding international property sales, and facing common problems is most unremarkable. Two of these factors relate to politics. Taiwan is not a member of the UN, so it cannot participate in discussions of common problems for indigenes. In addition, the agreement between New Zealand and the Separate Customs Territory of Taiwan, Penghu, Kinmen, and Matsu on Economic Cooperation (ANZTEC) was only recently signed (CNA, 2013), so the effectiveness of expanding the indigenous international property sales is not yet remarkable.

Regarding the implementation of the indigenes' international interactions in Taiwan, inviting them to attend cultural activities, conducting actions to international interflow, and encouraging cultural activities are more 
beneficial, whereas nominating representatives for economic conference, encouraging membership in international organizations, and encouraging attendance at international conferences are not exceptional.

As a result, different goals of international interactions can be achieved more effectively by using different methods. For example, by using the methods of inviting groups to cultural activities, encouraging cultural activities, and conducting actions to international interflow will help achieve the objectives of tracking the origins of indigenes' wisdom and promoting respect for global indigenous culture. The objectives of promoting selfconfidence and consciousness, enhancing international visibility, and studying experiences abroad correspond to the methods of encouraging attendance at international conferences. Although boosting tribes' tourism is significant for indigenous economics, the objective cannot be achieved using the current methods.

Finally, the study results suggest that Taiwan's indigene-related institutions should select the most effective methods to reach their goals. Although there is no effective way to achieve the goal of boosting tribes' tourism, the government should consider cooperation with other organizations, such as the Tourism Bureau, to give impetus to this goal. The current international interchange targets of supporting international affairs training are ineffective; perhaps the resource input is not sufficient and the implementation process has to be examined more. On the whole, the implementation of indigenes' international communication needs should be further boosted by the government.

\section{AUTHOR INFORMATION}

Chen Shan-Hua is an associate professor in the Graduate Institute of Educational Administration and Policy Development at National Chiayi University in Taiwan. She teaches courses in the sociology of education, multicultural education, teaching methodology, and qualitative research methods. While her early research addressed the educational experience of working-class students in Taiwan, her current research interests focus on indigenous students. Although not an aboriginal, she specializes in the education of indigenous and disadvantaged

students. She has received several project grants and awards from the National Science Council of Taiwan. Her research papers on indigenous and multicultural education have been published in related journals. E-mail: shanhua@mail.ncyu.edu.tw

\section{REFERENCES}

1. $\quad$ Austronesia Cultural Arts Festival. (2012). Austronesia cultural arts festival 2012. Retrieved from http://2012nandao.gem-imc.com.tw/index25.html

2. Chen, S.-H. (2012). The story of Orchid and Bataan Island. Indigenous Documents, 6, 7-12.

3. CNA (Central News Agency). (2013). ANZTEC: A special chapter on indigenous issues. Retrieved from http://www.cna.com.tw/News/aIPL/201307160411-1.aspx

4. Coolidge, T., \& Wang, Y.-W. (2013). Another of the keys to the world: Implications of ANZTEC. Retrieved from http://www.taiwanus.net/news/news/2013/201308111835271441.htm

5. MOE (Ministry of Education, R. O. C.). (2011). White paper of the indigenous education. Taipei: Author.

6. MOEA (Ministry of Economic Affairs, R.O.C.). (2013). Press release: MOEA affirms the signing of ANZTEC. Retrieved from http://www.moea.gov.tw/TNE/main/news/News.aspx?kind=1\&menu_id= 40\&news_id $=32$

7. Psacharopoulos, G., \& Patrinos, A. (Eds.). (1994). Indigenous people in Latin America. Washington, DC: World Bank. Retrieved from http://undesadspd.org/IndigenousPeoples/DeclarationontheRightsofIndigenousPeoples.aspx

8. Saaty, T. L. (1980). Analytic hierarchy process: Planning, priority, setting, resource allocation. New York: McGraw-Hill.

9. UNESCO. (2007). Declaration on the rights of indigenous peoples. Retrieved from http://www.un.org/esa/ socdev/unpfii/documents/faq_drips_en.pdf

10. UNESCO. (2013a). United Nations: Permanent forum on indigenous issues. Retrieved from http://undesadspd.org/IndigenousPeoples.aspx

11. UNESCO. (2013b). Endangered languages. Retrieved from http://www.unesco.org/new/en/culture /themes/endangered-languages/ 
12. United Nations. (2007). General assembly (GA/10612). Retrieved from http://www.un.org/News/Press/ docs/2007/ga10612.doc.htm

13. Yang, C.-H. (2012). The population in islands and countries: The contemporary visions of relationship history between Orchid Island in Taiwan and Bataan Ivatan in the Philippines. Hualien: National DongHwa University. 
NOTES 